\title{
Reviewed paper on biology of the Calpain proteolytic system
}

\author{
Javed Ahmed Ujan*, Sadaf Jumani, Sapna Waheed Memon and Majida \\ Narejo \\ Department of Zoology, Shah Abdul latif University, Khairpur 66020, Sindh-Pakistan \\ *Corresponding author's email: javed.ujan@salu.edu.pk \\ Citation \\ Javed Ahmed Ujan, Sadaf Jumani, SapnaWaheed Memon and MajidaNarejo. Reviewed paper on biology of the \\ Calpain proteolytic system. Pure and Applied Biology. Vol. 7, Issue 2, pp603-609. \\ http://dx.doi.org/10.19045/bspab.2018.70075
}

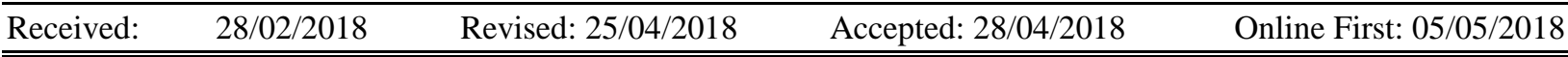

\section{Abstract}

The original calpain structure involved three molecules: two $\mathrm{Ca} 2+$-dependent proteases, mucalpain and m-calpain, and a third peptide. Calpastatin is an endogenous protein macromolecule that has a significant effect on calpain. In addition, calpain activity is believed to be affected by free calcium concentration due to the presence of calpain inhibitor substances. $\mu$-related degreed $\mathrm{m}$-calpain is a heterodimer conferred by the indivisible $28-\mathrm{kDa}$ fractional unit of currency and an $80-\mathrm{kDa}$ subunit that shares $55-65 \%$ sequence similarity in both proteases. In human order, there are fourteen calpain genes. The most studied calpain, known as calpain, is ubiquitous. Calpains play an important role in the characterization of macromolecules, leading to improved meat quality after slaughter. Although macromolecular deprivation in muscle atrophy is improved, and muscle growth rate is limited. This review summarizes the standard features of some of the calpain frameworks as well as the importance of the animal science calpain framework

Keywords: Calpain; Calpain inhibitor; Meat tenderization; Skeletal muscle growth

\section{Introduction}

The calpain proteolytic system is the most characteristic protein degradation system that causes meat tenderness. Calpains entrust cysteine proteases to calcium-dependent effects [1]. The framework is very sensitive to different levels of calcium, temperature and hydrogen ion concentrations and both tend to switch over the entire autopsy population [2]. Calpain exists in two forms within the chemical framework m-calpain and mu-calpain. For each of his or her activities, each atom is passionate about the calcium and the ubiquitous expression. The word $\mathrm{m}$-calpain and $\mu$-calpain implies support for calcium fixation necessary for activation [3].n general, m-calpain requires $1000 \mu \mathrm{M}$ - a thousand $\mu \mathrm{M} \mathrm{Ca} 2+$ for the maximum activity of 0.5 , while lower amounts of $\mathrm{Ca} 2+$ require $\mu$-calpain activity at $5 \mu \mathrm{M}-65 \mu \mathrm{M}$ [4]. Subtypes that target both of these Calpains to cleave constant myofibrillar macromolecules have been observed but do not significantly reduce globulin and simple proteins $[5,6]$. It may have been performed on porcine skeletal muscle at the beginning of removal of calpain, after which it has been previously suggested that the catalyst may be included in the turnover from the putative myofibril macromolecules [7]. According to the results of this study, the characteristics of 
macromolecules were applied to determine their property [7]. The relocation of two peptide chains in SDS-PAGE concluded that calpain survived as two subunit hybrids of the $80 \mathrm{kDa}$ and $30 \mathrm{kDa}$ subunits. From this investigation, it was found that decontaminated Calpains require these abilities to disrupt or dislodge those Z-disks and largely disrupt the $\mathrm{M}$ line to initiate some effects on troponin $\mathrm{T}$ and troponin $\mathrm{I}$, but not the overall structure of the super-muscle. Auxiliary examinations associated with calpain substrates showed that a large number of macromolecules linked by Z-loop macromolecules and costamere via muscle structure were fragmented [8]. The purpose of this brief review article is to compare all available information about calpain, its history, isolation, structure, importance and its role.

\section{Isolation of calpain}

Calpain has discovered well-evolved organisms in a variety of cell types, with a major portion associated with myofibrillar skeletal muscle. The basal detection of calpain, previously identified as a calcineurin, may have surpassed 1981 when the protein was extracted from the protein in rabbit skeletal muscle [9]. Protein expression describes that Calpains are involved in the perception of two subunits, 80-KDa and 30$\mathrm{KDa}$, in SDS pages. Through the use of gel filtration chromatography, additional calcium-triggered proteases of similar atomic weight were found on rodent hearts for approximately the same length of time [10]. In the human body, a detergent for calpain is prepared from the cytosol parcel to homogenize platelets using a mixture of gel filtration chromatography and trend chromatography. This gives up two separate polypeptides of $80 \mathrm{kDa}$ and $27 \mathrm{kDa}$. Unique body tissue survey [11]. Sterilize the calpain that begins with skeletal muscle and remember it like a heterodimer containing $78 \mathrm{KDa}$ and $28 \mathrm{KDa}$ proteins. Different studies have revealed that Calpains isolated from bovine and brain are almost similar in weight to their subnuclei, two of which are heterodimers composed of $75 \mathrm{kDa}$ and 29 $\mathrm{kDa}$ subunits [12]. The goal is to compare subunit weights of calpain in some animal types for comparison.

\section{Background information on the calpain system}

The pre-historic age of calpain is in contrast to 1964 , once calpain was found in the brain and eye lens. Protease performance is caused by intracellular amino acid proteases and has the best activity at neutral pH [13]. Calpain's actions are mainly due to having two major isoforms $\mu$-calpain and m-calpain. These two isoforms require different amounts of calcium in vitro, and their names suggest that they help promote the microscopic and millimolar concentrations of intracellular $\mathrm{Ca} 2+[14]$. In 1989, $\mu$-calpain and m-calpain were originally used to consider the need for micromolar and millimolar amounts of $\mathrm{Ca} 2+$ for his or her activation, and their area units are expressed as current Calpains. About thirteen years ago, it had revealed that the calpain family contained one-third of the calpain family. The transition in calpain 3 has led to the subtypes of sex-recessive inherited and progressive limb-grid genetic diseases called genetic disease type 2A [15]. Once mcalpain has been isolated from muscle extracts, calpastatin can be found to inhibit $\mu$ calpain and m-calpain.

\section{Biochemical structure and activation of calpain}

Generally, Calpains have similar characteristics that they are scattered in the cytoplasm of the internal cysteine protease, they force calcium binding to stimulate the full effect [16]. Isolation of fifteen isoforms from calpain has been characterized as a possible general or tissue-specific restriction [17]. Commonly considered isoforms are the ubiquitous mu-Calpains and $\mathrm{m}$-Calpains, It confers a relatively heterodimeric structure, 
but it will promote differential focusing of ionized calcium. In vitro, microcalorimets of calcium require priming of $\mu$-calmodulin, while m-calprotectin requires millimolar amounts.

The heterodimeric structures of vertebrate $\mu$ calpain and m-calpain, composed of $80 \mathrm{kDa}$ reactant subunits, can also serve as a reliable point for the $28 \mathrm{kDa}$ management subunit. The reactant subunits of $\mu$-calpain and calpain, called calpain-1 and calpain-2, respectively, are quite different in any case. Most of them are separated along those proteins in four regions or regions (Figure 1), where the $\mathrm{N}$-terminal region of the reactant subunit is designated as similar to Region I. Region II is generally implicated as to elucidate which regions of the reactants that cysteine, histidine and asparagine amino residues are important for the proteolysis of calpain.To link the reactant region to the $\mathrm{C}$ terminal region, domain iii includes residues that work about with the plasma membrane and calcium binding. Finally, Domain IV has four $\mathrm{EF}$ hand sequences responsible for calcium binding. The small administrative subunit (Calpain-4) is regular for the $\mu$ - and m-Calpain subtypes and is created by Domains V and VI, which have hydrophobic residues that help achieve cinematic collaboration (Domain V) and extra Calciumbinding EF sequence (Domain VI). The catalytic and regulatory subunits remain linked under inactive conditions and may continue to interact upon activation. Following calcium binding, $\mu$ - and $\mathrm{m}$-calpain autolysis, which self-cleave alternately, the $\mathrm{N}$-terminal packs of the giant and small subunits should perform complete proteolysis. The molecular weight of the 80 $\mathrm{kDa}$ subunit is $76 \mathrm{kDa}$ or $78 \mathrm{kDa}$, respectively, which is reduced to $18 \mathrm{kDa}$ with a small subunit of normal calpain-1 or -2 molecular weight. Although activation requires such self-splitting, it needs to be challenged by the fact that autolysis reduces the preconditions for proteolytic movement of calprotectin [18]. Thereby increasing the confidence that calprotectin may be activated after physiological calcium translocation degree. In addition, calcium binding causes a conformational change in the calpain structure, allowing proteolytic movement of the protein residues of the reactants together [19].

\section{The importance of calpain}

The importance of Calpains, especially $\mu$ calpain, to verify post-mortem softening required for $\mu$-calpain may also need to be substantially suppressed as the post-mortem chemical changes in these organisms [20]. Western blotting Studies from these animals show that the purpose of spoilage of de nodulins, dystrophin, vincristin and troponin units is much better than those of managed animals, in the case of myofibrillar proteins. Confirmation from survey needs and additional suggestion that two calpain subtypes play a unique role throughout the post-mortem experience. Data from bovine myofibrils suggest that $\mu$-calpain is also among those motivated by rapid sections (the first three days) [21]. However, the fact from slaughter of longisimusdorsi (LD) pig suggests that m-calpain is an additional stabilizing agent for $\mu$-calpain and that it does not stimulate throughout the first 1-8 hours after slaughter (animal slaughter) [22]. In addition, unnatural fixation from intrinsic $\mathrm{Ca} 2$ + throughout the autopsy may stop mcalpain from advancing these chemotherapeutic processes should occur [23].

Function of calpain system in bone growth There is ample evidence that Calpains play a major role in typical and postnatal skeletal muscle dilatation, muscle wasting and the unfortunateness of muscle pretense. Many tests need to demonstrate that the calpain framework also has normal skeletal muscle development. Addition of beta-adrenergic receptor agonist tissue to a living creature 
increases the rate of aggression by $1030 \%$ [24]. Although different examinations were performed with different b-adrenoceptor agonists using different species, the individual states produced subtle, unique results. Some studies suggest that $\beta$ adrenergic receptor agonist tissue increases the rate and effectiveness. It should be noted that the $\beta$-adrenergic painful tissue affects the role of the calpain framework [25]. In addition, increased muscle protease inhibitor activity [26]. The increase ranged from 52\% to $430 \%$ [27]. Muscle m-calpain exercise may be reduced or unchanged, while mcalpain movements appear and increase. It is important to consider that $\mu$ - and m-calpain movements may be reduced. Skeletal skepticism in respiratory phenotype sheep may be more significant than $3040 \%$ of those in semi-siblings who do not express respiratory traits [28]. Of the affected copepods, Calpastatin requires $68,126 \%$ of aiding, which is better than a typical lamblike muscle and also calpastatin in the aesthetically pleasing corpus y muscle. This finding suggests that an increase in skeletal muscle growth may begin with a decrease in muscle protein deprivation. This tight muscle protein deprivation rate is associated with a decrease in calpain skeleton motility [29]. Post-test reports say that calpain action may be necessary, units will pass through the G1 to $\mathrm{S}$ phase of the mitotic cycle, and that an additional combination of myoblasts is needed [30]. This provides that improved calpain action may be associated with increased amounts of myoblasts throughout the muscle improvement. Development of C2 C12 myoblasts maintains m-calpain [31]. This may be due to the beta-adrenergic pain of tissue developing the animal and seems to have less impact on the peri-calpain around the calpain than it is around Calpastatin.

\section{Calpain function in skeletal muscle}

Calpains will undergo a putative protein change by restriction protein disruption and then focus on the ubiquitin proteasome deprivation pathway. m-calpain is automatically resolved from the full-length $80 \mathrm{kDa}$ structure into the $78 \mathrm{kDa}$ expression by expanding its $\mathrm{Ca} 2$ susceptibility, which More prone to more than 10 times. Preactivated $\mathrm{m}$-calpain is confined to the surface of the membrane, and it has also been found that unimpeded diffusion of full-length mcalpain at a micromolar $\mathrm{Ca} 2$ site with cells is rapidly maintained by not less than a limited extent A certain time. Caocalin autolysis increases $\mathrm{Ca} 2$ susceptibility in the localization of calcium phospholipids. Preactivated calpain will ideally be set up to facilitate rapid resealing of the membrane, and the process is said to depend on dysferlin and reorganization of the cytoskeleton to calpain [32]. In vivo, m-calpain has been shown to be involved in membrane repair, and its protective role in skeletal muscle is also demonstrated. Important information suggests that calpain needs to be set entirely to have a special effect on skeletal muscle protein. Myosin gradually degrades, and this modest deprivation is limited to a pair of light chain cleavage.

Undenatured actin is not cleaved by $\mu$-calpain or m-calpain. Both $\mu$ - and $\mathrm{m}$-calpain rapidly cleave troponin $\mathrm{T}$, desmin, vincristine, talin, spectrin, nebulin, and also titin; greater amounts progressively cleave troponin I, filamin, C-protein, Dystrophin and tropomyosin; and gradually cut $\alpha$-actin and m-protein [33]. The deposition of calpain skeletal muscle protein leads to the unfortunate N2 line, which then leads to the complete unfortunateness of the Z-disk, giving up a hole in the center of the sarcomereus. At the same time, the I-band is periodically reduced due to the infiltration of troponin and tropomyosin. The reduction of this Z-plate structure is due to the excretion of $\alpha$-actinin in the Z-plate in an almost complete structure. Although numerous studies show that myosin, actin, and $\alpha$-actinin 
are degrading by calpain, whether these studies lead to the use of non-denatured proteins may become obscure. Both $\mu$ - and m-calpain rapidly degrade denatured actin, myosin and $\alpha$-actinin. Calpains specifically cleave small amounts of cytoplasmic proteins, which essentially bind to protein kinases and phosphatases.

They do not cause extensive degradation of sarcoplasmic protein under moderate debris [34].

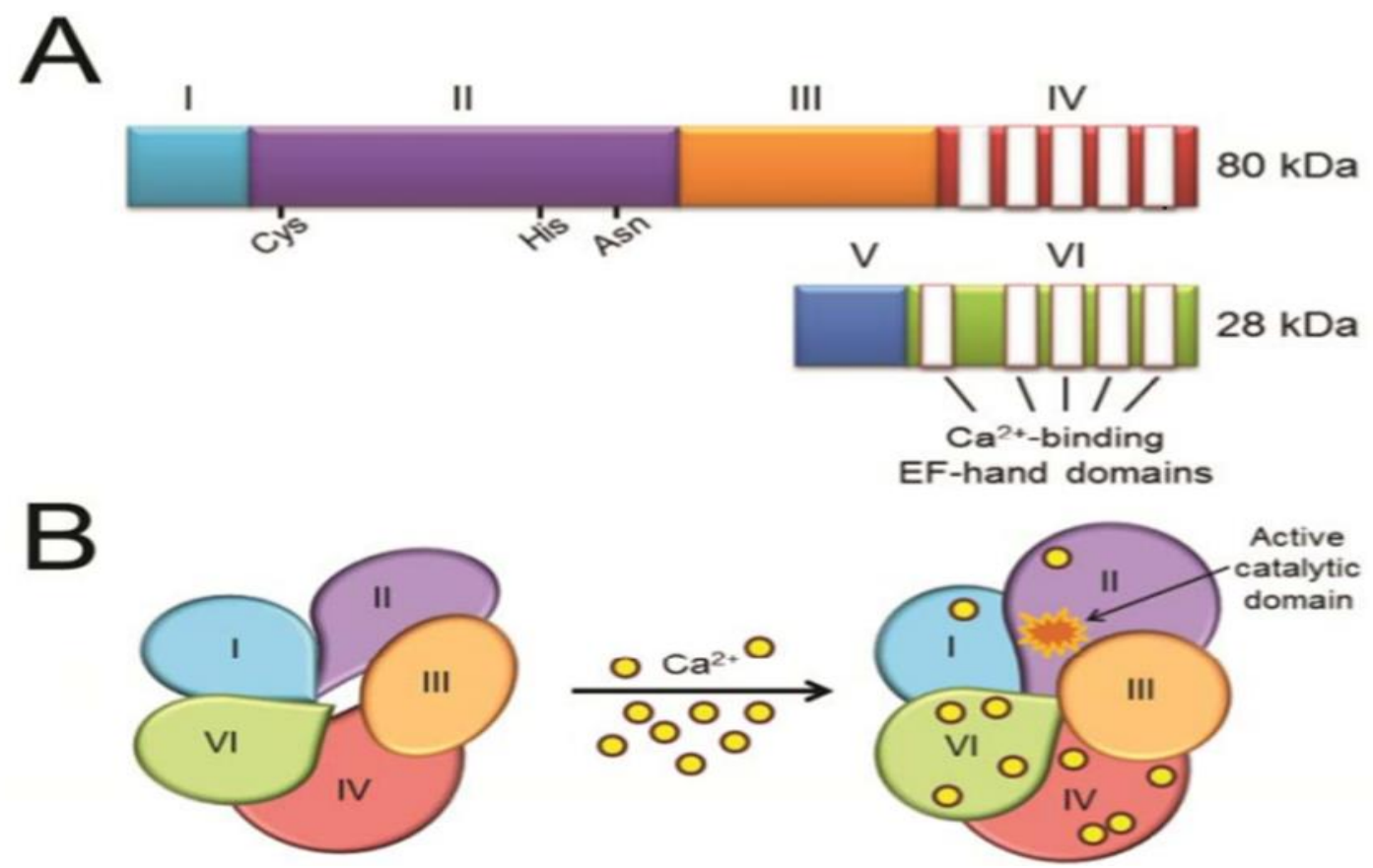

Figure 1. Shows the biochemical structure and activation of $\mu$-calpain and $m$-calpain.

A) Heterodimers associated with the 'typical' calpain, $\mu$-calpain and $\mathbf{m}$-calpain distribution align into a huge catalytic subunit and a small number of regulatory subunits. Domain II of the giant subunit includes amino acid residues that are conspicuous for proteolysis. Calcium binding occurs predominantly at EF hand sequences located on domains IV and VI. B) Autolysis of Calcium with Calpain Extract and Conformational Changes in Protease Structures. Specific amino acid residues are placed in Domain II to promote proteolysis

\section{Conclusion}

Many scientists are engaged in their study of the calpain system and their study concluded that the calpain family consists of three distinct molecules, including two ca2 + dependent proteases, $\mu$-calpain and $\mathrm{m}$ calpain, As well as a protein calpastatin without known activity in addition to inhibiting both Calpains. Both $\mu$-calpain and m-calpain are circular dimers surrounded by the same $28 \mathrm{kDa}$ subunit and the $80 \mathrm{kDa}$ subunit, which together with both proteases assign 55-65\% sequence homology. Calpains play an important role in characteristic protein degradation systems that cause meat tenacity in the cadaver. Although protein deprivation enhances muscle atrophy and limits muscle growth rate.

\section{Authors' contributions}

Conceived and designed the experiments: JA Ujan, Performed the experiments: S Jumani, Analyzed the data: MP Narejo, Contributed materials/ analysis: SW Memon, Wrote the paper: JA Ujan \& S Jumani. 


\section{Acknowledgement}

First Author is highly thankful to the coauthors for their value added contribution throughout the study; special support of Ms Sadaf Jumani is highly appreciated for completing this review paper.

\section{References}

1. Goll DE, Thompson VF, Li H, Wei WEI, \& Cong J (2003). The Calpain system. Physiol Rev 83(3): 731-801.

2. Melloni E, Salamino F \& Sparatore B (1992). The Calpain - CalpastatinSystem in Mammalian Cells: Properties and Possible Functions. Biochimie 74(3): 217223.

3. Cong J, Goll DE, Peterson AM \& Kapprell H. P (1989). The role of autolysis in activity of the $\mathrm{Ca} 2+$-dependent proteases (mu-calpain and m-calpain). J Biol Chem 264(17): 10096-10103.

4. Goll DE, Thompson VF, Taylor RG \& Christiansen JA (1992). Role of calpain system in muscle growth. Biochimie 74(3): 225-237.

5. Dayton WR, Reville WJ, Goll DE \& Stromer MH (1976). A Ca2 + activated protease possibly involved in myofibril turnover. Subcellular Localization of Proteases in Pig Skeletal Muscle. J Cell Biol 70(1): 1-8.

6. Koohmaraie, $\mathrm{M}$ (1992). The role of $\mathrm{Ca} 2+$ -dependent protease (calpain) in postmortem proteolysis and meat tenderness. Biochimie 74(3): 239-245.

7. Dayton WR, Reville WJ, Goll DE \& Stromer MH (1976). Ca2 + activating proteases possibly involved in myofibrillar proteins turnover - partial characterization of purified enzyme. Biochemistry 15: 2159-2167.

8. Taylor RG, Geesink GH, Thompson VF, Koohmaraie M, \& Goll DE (1995). Is Zdisk degradation possibel for postmortem tenderization. J Anim Sci 73(5): 13511367.

9. Tsuji S \& Imahori K. (1981). Studieson $\mathrm{Ca} 2+-$ activated neutral protease in rabbit skeletal muscle I. The Characterization of
$80 \mathrm{~K}$ and $30 \mathrm{~K}$ subunits. J Biochem 90(1): 233-240.

10. Croall DE \& De Martino GN (1984). Purification and Characterization of Calcium-Dependent Proteases from rat liver. Biochemistry. Biophys 258(9): 56605665.

11. Suzuki K, Ishiura S, Tsuji S, Katamoto T, Sugita H \& Imahori K (1979). Calcium activated neutral protease from human skeletal muscle.FEBS Letters 104(2): 355358.

12. Kubota S, Onaka T, Murofushi H, Ohsawa N \& Takaku F (1986). Purification and characterization of high calciumrequiring neutral proteases from porcine and bovine brains. Biochemistry 25(26): 8396-8402.

13. Ohno S, Emori Y, Imajoh S, Kawasaki H, Kisaragi M \& Suzuki K (1984). Evolutionaryorigin of the calciumdependent protease by fusion of genesfor athiol protease and a calcium binding protein. Nature 312(5994): 566.

14. Glass JD, Culver DG, Levey AI \& Nash NR (2002). Very early activation of mcalpain in peripheral nerve during Wallachian Degeneration. Neurology Sci 196(1): 9-20.

15. Beckmann JS \& Spencer M (2008). Calpain 3, the gatekeeper of proper sarcomere assembly, turnover and maintenance. Neuromuscular Disorders 18(12): 913-921.

16. Croall DE \& Ersfeld K (2007). The Calpains: modular designs and functional diversity. Genome Biology 8(6): 218.

17. Sirimachi H, Hata S \& Ono Y (2011). Calpain chronicle - an enzyme family under multidisciplinary characterization, Proc Japan Acad Series B 87(6): 287-327.

18. Edmunds T, Nagainis PA, Sathe SK, Thompson VF \& Goll DE (1991). Comparison of autolyzed and unautolyzed forms of $\mu$ - and $m$-calpain from bovine skeletal muscle. Biochim Biophysics Acta Protein Struct Mol Enzymol 1077(2): 197208.

19. Moldoveanu T, Hosfield CM, Lim D, Elce JS, Jia Z \& Davies PL (2002). A Ca2 + 
switch is aligns the active site of calpain. Cell 108(5): 649-660.

20. Geesink G H, Kuchay S, Chishti A H. and Koohmaraie M (2006). $\mu$-Calpain is essential for post-mortem proteolysis of muscle proteins 12. J Anim Sci 84(10): 2834-2840.

21. Taylor RG, Geesink GH, Thompson V F, Koohmaraie M \& Goll DE (1995). Is Zdisk degradation responsible for postmortem tenderization? J Anim Sci 73(5): 1351-1367.

22. Sensky PL, Parr T, Bardsley RG \& Buttery PJ (1996). The relationship between plasma epinephrine concentration and the activity of the calpain enzyme system in porcine longissimus in the longest muscle. J Anim Sci 74(2): 380-387.

23. Boehm ML, Kendall TL, Thompson VF \& Goll DE (1998). Changes in theCalpains and calpastatinduring postmortem storage of bovine muscle. J Anim Sci 76(9): 24152434.

24. Yang YT \& McElligott MA (1989). Multiple actions of beta-adrenergic agonists on skeletal muscle and adipose tissue. Biochem J 26(1): 1.

25. Forsberg NE, Ilian MA, AlBar A, Checke PR \& Wehr NB (1989). Effects of cimaterol on rabbit growth and myofibrillar protein degradation and on calcium-dependent proteinase and calpastatin activities in skeletal muscle. $J$ ANIM SCI 67: 3313-3321.

26. Higgins JA, LasslettY V, Bardsley RG \& Buttery PJ (1988). The relation between dietary restriction or clenbuterol (a selective $\beta 2$ agonist) treatment on muscle growth and calpainprotinase (EC 3.4.22.17) and calpastatin activities in lamb. Br meat $J$ Nutr 60(3): 645-652.

27. Kretchmar DH, Hathaway MR, Epley RJ \& Dayton WR (1989). In vivo effects of a $\beta$-adrenergic agonist on activity of calcium-dependent proteinases, their specific inhibitor, and cathepsins $\mathrm{B}$ and $\mathrm{H}$ in skelatl muscle. Arch Biochem Biophys 275(1): 228-235.

28. Cockett NE, Jackson SP, Shay TL, Nielsen D, Moore SS, Steele MR \& Georges M (1994). Chromosome localization of the callipyge genes in sheep (Ovisaries) using bovine DNA markers. Proc Natl Section Acad Sci USA 91(8): 3019-3023.

29. Koohmaraie M, Shackelford SD, Wheeler TL, Lonergan SM \& Doumit ME (1995). A muscle hypertrophy in lamb (Callipyge): characterization of effects on muscle growth and meat quality traits. $J$ Anim Sci 73(12): 3596-3607.

30. Barnoy S, Glaser T \& Kosower NS (1997). Calpain and Calpastatin in myoblast differentiation and fusion: effects of inhibitors. BBA-Mol Cell Res 1358(2): 181-188.

31. Cottin P, Brustis JJ, Poussard S, Elamrani N, Broncard S \& Ducastaing A(1994). Ca $2+$-dependent proteinases (calpain) and muscle cell differentiation, BBA-Mol Cell Res 1223(2): 170-178.

32. Gailly P, De Backer F, Van Schoor M \& Gillis JM (2007). In situ measurements of calpain activity in isolated muscle fibers from normal and dystrophin-lacking mice. J Physiol 582(3): 1261-1275.

33. Tan F C, Goll D E and Otsuka Y (1988). Some Properties of Millimolar $\mathrm{Ca} 2+$ dependent Proteinase from Bovine cardiac muscle. J Mol cell Cardiol 20(11): 983997.

34. Arthur JSC, Elce JS, Hegadorn C, Williams K \& Greer PA (2000). Distruption of the mourine calpain small subunit gene, Capn 4: calpain is essential for embryonic development, but not for cell growth and division. Mol Cell Biol 20(12): 4474-4481. 